\title{
Discutindo a concepção de noticing no momento do julgamento pragmático à luz do paradigma conexionista
}

Lydia Tessmann Mülling

Mestranda no programa de Pós-Graduaçāo em Letras da UCPEL

\section{MÁrcia Cristina Zimmer}

Doutora em Lingüistica e Letras pela Pontifícia Universidade Católica do Rio Grande do Sul (2004).

Atualmente é professora adjunto da Universidade Católica de Pelotas. Tem experiência na área de Lingüistica, com ênfase em Psicolingüistica, atuando principalmente nos seguintes temas: conexionismo e aquisiçāo da linguagem, leitura em L2, produção oral em inglês (L2), com ênfase na interaçāo entre memória implicita e explicita e aspectos fonético-fonológicos do input.

Resumo: A pesquisa sobre a aprendizagem da L2 revela que pouca atenção tem sido dedicada ao papel desempenhado pela consciência no desenvolvimento da competência pragmática. Considerando que a atençāo às formas lingüísticas, às funçōes da lingua e seus sentidos, bem como ao contexto é necessária para que ocorra o aprendizado da pragmática da L2, este trabalho apresenta dados sobre o julgamento pragmático em alunos de inglês (L2), discutindo-os à luz da teoria do noticing e do conexionismo.

Palavras-chave: consciência; noticing; pragmática; julgamento; conexionismo
Abstract: Second language learning research has revealed that little attention has been placed on the role of consciousness in the development of pragmatic competence. Departing from the assumption that attention to linguistic form and function, as well as the context, is a necessary condition for $L 2$ pragmatic learning, this paper focuses on how Brazilian learners of English judge sentences that are pragmatically inappropriate and whether they are able to perceive pragmatic violations. The results are discussed within a connectionist framework.

Keywords: awareness; noticing; pragmatics; judgment; connectionism 


\section{Introdução}

Os aprendizes de uma língua estrangeira constroem um sistema híbrido para a comunicação - a interlíngua. Segundo Selinker (1972), o aprendiz, em situação formal de aprendizagem ou em contexto informal, depara-se com três sistemas lingüísticos: o da sua língua materna, o da língua-alvo, que ele pretende dominar, e o que é produzido por ele na tentativa de torná-lo semelhante ao anterior. Portanto, a interlíngua pode incluir padrões de ambos os sistemas em contato, língua materna e língua estrangeira ${ }^{1}$, e o aprendiz aplica estratégias adaptativas com a finalidade de estabelecer comunicação.

Podemos perceber que a interlíngua é caracterizada como um sistema que envolve processos cognitivos e que acontece dentro de um continuum em direção à língua que se pretende adquirir. $\mathrm{O}$ aprendiz desenvolve maior proficiência, na medida em que consegue organizar o material lingüístico dentro desse sistema em constante formação. Contudo, cerca de 5\% dos aprendizes alcançam sucesso absoluto na tentativa de atingir o nível de um falante nativo. Os outros $95 \%$ apresentam diferentes graus de interlíngua que tendem a se tornar semelhantes à competência do nativo, conforme a exposição à L2 (SELINKER, 1972). Em ambiente formal, é possível notar que os aprendizes apresentam inadequações de pronúncia, entonação, ritmo, morfologia, sintaxe, semântica e pragmática. Essas diferenças, principalmente nos aspectos de ritmo, entonação e pragmática, são reconhecidas nos aprendizes como "sotaque". Nós carregamos o sotaque durante todo o nosso percurso como aprendizes e falantes de uma L2. À medida que somos expostos à língua-alvo, adquirimos a capacidade de organizar os aspectos gramaticais e pragmáticos dentro da interlíngua. Cook (2003) argumenta que os aprendizes de uma L2 deveriam ser vistos como falantes multicompetentes em vez de falantes não-nativos que apresentam deficiências lingüísticas, visto que esses falantes são capazes de manipular dois sistemas lingüísticos e mostram-se perspicazes em compensar
'O presente trabalho não fará distinção entre os termos LE (língua estrangeira) e L2 (segunda língua). 
insuficiências lingüísticas lançando mão de estratégias presentes na sua L1.

Sabemos, portanto, que o aprendiz avança em direção à língua alvo à medida que passa a perceber a existência de um sistema de regras subjacente à língua que ele utiliza. A sala de aula de língua estrangeira é, portanto, um local em que se pode perceber o desenvolvimento da interlíngua e sua evolução. Um professor consciente da complexidade dos processos que ocorrem na interlíngua de seus aprendizes tem melhores condições de orientar o processo de aprendizagem de seus alunos, tanto no nível fonológico, quanto no morfológico, no semântico ou no pragmático.

Escolhemos investigar o aspecto pragmático da língua, especialmente por observarmos a rara abordagem desse aspecto por parte dos professores de L2, que geralmente não possuem vivência em países de fala inglesa, e também por observar a produção lingüística dos aprendizes. Ao tratar de questões referentes à pesquisa em pragmática, Bardovi-Harlig (2001) afirma que, se for observarmos o currículo que orienta os ambientes formais, notaremos que a avaliação dos aprendizes de inglês como língua estrangeira é geralmente feita com exames orientados para a competência gramatical. Geralmente avaliamos nossos alunos com questões que investigam a gramática, deixando de lado questões que contemplem aspectos importantes da linguagem, como a semântica e a pragmática. Além disso, a maioria dos professores de LE que compartilham a mesma L1 de seus aprendizes não vivenciou nenhuma experiência em uma comunidade lingüística de falantes nativos e tampouco dedica sua atenção a exercícios que objetivem o exercício da consciência pragmática. Assim, podemos correr o risco de perpetuar um ciclo vicioso que não atenta para os aspectos pragmáticos pertencentes à língua-alvo e, como conseqüência, deixar de contribuir para que nosso aluno torne-se mais competente comunicativamente. 


\section{Revisando as competências: gramatical, pragmática e comunicativa}

Quando pensamos em competência comunicativa, fazemos necessariamente referência ao trabalho de Chomsky (1965), que cunhou o termo "competência lingüística”, através da criação da antinomia competênciadesempenho, sendo a competência referente às habilidades abstratas do falante, ao conhecimento lingüístico, que é sintático por natureza e construído com bases na capacidade inata do falante e no input recebido durante a infância. Já o desempenho diz respeito ao comportamento lingüístico do falante, que é proveniente da competência lingüística, dos aspectos sociais e psicológicos envolvidos na produção lingüística.

Diferentemente de Chomsky, Hymes (1972) considera a interação social como elemento fundamental da linguagem e propõe que o termo "competência comunicativa" seja utilizado com referência ao uso da língua dentro de um contexto social, considerando as condições sociais e os aspectos de adequação sociolingüística. A teoria da competência comunicativa postulada por Hymes (1972) refere-se ao que o falante precisa saber para ser comunicativamente competente dentro de uma comunidade lingüística de fala. Essa competência envolve não somente os aspectos gramaticais da língua, mas a negociação de sentido, a percepção do contexto e do papel do interlocutor.

A proposta de Hymes ocasionou uma mudança no paradigma de aquisição de uma língua. Primeiro, investigava-se a linguagem no nível da sentença; lentamente, passou-se a incluir investigações no campo da semântica, da pragmática, e, paulatinamente, foram-se incluindo variáveis de ordem cultural. Por conseguinte, esta quebra de paradigma também se refletiu sobre a maneira de se ensinar e aprender uma L2, sob a forma da abordagem comunicativa.

Ao analisarem a concepção de competência comunicativa elaborada por Hymes (1972), Canale e Swain (1980) fazem uma revisão sobre o conceito de 
competência comunicativa e propõem três dimensões para essa competência, com o objetivo de fornecer definições que auxiliem a instrução pedagógica e a condução de pesquisas em Lingüística Aplicada, visto que havia grande desacordo quanto ao conceito de competência comunicativa. Os três componentes propostos são as competências gramatical, sociolingüística e estratégica. A competência gramatical diz respeito ao conhecimento do código lingüístico, a gramática e o léxico. A competência estratégica diz respeito ao domínio de estratégias da comunicação verbal e não-verbal que os falantes utilizam para compensarem falhas na comunicação. A competência sociolingüística inclui regras socioculturais de uso e regras do discurso. Esta competência diz respeito à produção de enunciados de acordo com o contexto, com a situação social do interlocutor, de acordo com as normas e as convenções que cada língua possui. Uma vez que a pragmática não está presente entre esses três componentes da competência comunicativa, a habilidade pragmática foi incluída dentro da competência sociolingüística, sob a forma de regras de uso. Hymes (1972) também se referiu a essa habilidade como "as regras de uso sem as quais a gramática não teria uso, serventia”. Canale (1983) acrescenta um quarto componente à noção de competência comunicativa, o qual denominou competência discursiva. Esta competência refere-se ao ato de interpretar o texto relacionando a forma com o conteúdo, para apreender o sentido da palavra escrita.

O marco teórico desenvolvido por Canale e Swain (1983) tem sido freqüentemente citado por pesquisadores no mundo todo. Uma década após a publicação da primeira versão do conceito de competência comunicativa de Canale e Swain (1980), Bachman (1990) sugere um modelo de competência comunicativa que inclui a competência pragmática.

A forma como os componentes da competência comunicativa interagem entre si tem sido fonte de vários debates e pesquisas. O que parece acontecer é que o 
falante se torna mais competente conforme a experiência lingüística e a freqüência do input, tanto na sua L1, quanto na L2. A pragmática, um dos componentes da competência comunicativa, diz respeito à linguagem, aos seus usuários e às significações que ela pode possibilitar. Esse conhecimento não depende somente do conhecimento gramatical, mas também do entendimento do contexto, das regras culturais, das normas e convenções que estão presentes no momento da interação.

A pragmática da interlíngua investiga a aquisição da pragmática de uma L2 por falantes não-nativos. Nas teorias de aquisição de uma L2, a pragmática geralmente aparece como uma restrição no conhecimento sintático ou não é reconhecida como um conhecimento cujo desenvolvimento mereça considerações teóricas (KASPER, 1996).

No entanto, é possível notar o crescimento da produção científica que aborde questões referentes à pragmática da interlíngua, que compreende a aquisição e o uso da pragmática da L2 (BARDOVI-HARLIG \& DÖRNYEI, 1998; ELLIS, 1992; NIEZGODA \& ROVER, 2001; SCHAUER; 2006). Grande parte das pesquisas tem como objetivo verificar como os falantes não-nativos realizam atos de fala, tomam turnos ou permanecem em silêncio, durante o ato comunicativo. Conforme BardoviHarlig (2001), os atos de fala têm sido alvo das pesquisas porque possuem um marco teórico analítico comum, o qual facilita comparações entre estudos de diferentes línguas.

Muitas pesquisas consideram que as fórmulas semânticas que regem os atos de fala não são universais. Logo, há diferenças entre as línguas, e tais distinções podem levar o aprendiz de uma L.2 a transferir as regras que regem o uso de sua L1 para a sua produção na L2. Em função disso, também adotaremos a visão de que os atos de fala podem ser realizados com intenções diferentes nas línguas do mundo. Kasper (1996, p. 119) define a transferência pragmática como "o uso do conhecimento pragmático da L1 para entender ou desempenhar ações na L2". Os aprendizes utilizam a 
${ }^{2}$ Para que a pragmática pudesse ser melhor investigada, Leech (1983) a classificou sob a forma de dois componentes: a pragmalingüística e a sociopragmática. A pragmalingüística se refere aos recursos utilizados para realizar a comunicação e conceber relações de sentido. Esses recursos incluem estratégias pragmáticas, como objetividade, o uso de fórmulas lingüísticas que podem intensificar ou amenizar o ato comunicativo. A sociopragmática é definida por Leech (1983, p.10) como "a interface social da pragmática "que se refere à percepção dos participantes que subjazem o ato comunicativo, no que diz respeito às relações de poder, às obrigações e aos direitos dos transferência como estratégia comunicativa, pois utilizam um conhecimento que possuem em sua L1 e o transferem, tentando adaptá-lo, para empregá-lo na L2. A transferência pragmática pode levar o aprendiz ao acerto, mas, por outro lado, podem ocorrer inadequações pragmáticas tanto de ordem sociopragmática quanto pragmalingüística ${ }^{2}$. Embora um grande número de pesquisas investigue a produção; há alguns poucos estudos que investigam a questão da percepção, do processamento e do julgamento, quanto ao aspecto pragmático da L2. Talvez por esse fato, a elaboração de uma teoria sobre a pragmática esteja tão distante das discussões centrais que ocorrem no campo da aquisição de uma segunda língua.

Preocupados com questão da consciência quanto aos aspectos pragmáticos da L2 e com a relação entre percepção e instrução, Bardovi-Harlig e Dörnyei (1998) desenvolveram um estudo, premiado pela TESOL ( Teachers of English to Speakers of Other Languages), investigando até que ponto os aprendizes de uma L2 estão conscientes das diferenças entre sua própria produção e a produção de falantes nativos, no que diz respeito aos aspectos gramaticais e pragmáticos da língua-alvo. Vários estudos têm demonstrado haver um desequilíbrio entre os conhecimentos pragmático e gramatical dos aprendizes de L2. Além disso, esses estudos vêm apontando que o desenvolvimento do conhecimento gramatical não garante o desenvolvimento pragmático do aprendiz. Logo, a variável proficiência lingüística pode não ser fator determinante na aquisição da competência pragmática. Em contextos onde a língua inglesa é ensinada como língua estrangeira, como, por exemplo, no Brasil, a diferença entre os conhecimentos pode ocorrer devido a dois fatores principais: a disponibilidade do input e a falta de atenção às características, saliências do input. Para Bardovi-Harlig e Dörnyei (1998.) interessa saber se os aprendizes de uma L2, no caso o inglês, são sensíveis às diferenças que ocorrem entre a sua produção e a língua-alvo, no que concerne principalmente ao aspecto pragmático. 


\section{Discutindo a aquisição da pragmática da L2 e o paradigma conexionista}

O falante bilíngüe, aprendiz de uma L2, reconhece seu interlocutor e a si mesmo como detentores de um mesmo par de línguas: português e inglês. Sabendo disso, o aprendiz mostra-se capaz de lançar mão de elementos de uma e outra língua, durante o ato comunicativo. No entanto, muitas vezes o aprendiz produz formas inadequadas, que divergem das tidas como alvo na L2. Essas formas são provenientes do entrincheiramento ${ }^{3}$ dos dois padrões lingüísticos que o aprendiz manipula: a L1 e a L2. O sujeito, em seu processo de aprendizagem, é exposto ao input da L2 e, além disso, traz consigo toda sua experiência oriunda da exposição à L1. Esta experiência origina generalizações do conhecimento da L1 e da L2, tanto no que diz respeito ao conhecimento fonéticofonológico, quanto ao semântico e o pragmático.

O conexionismo apresenta como premissa central a formação do significado a partir de complexos padrões de atividade entre os neurônios, por meio do processamento distribuído em paralelo. Assim, a L1 e a L2 não estão posicionadas em compartimentos estanques, que podem se tornar inativos - desligados - segundo a vontade do falante. Conforme o paradigma conexionista, os dois sistemas encontram-se interagindo, em competição, o que possibilita e serve como evidência para a transferência lingüística (MACWHINNEY, 2001). Uma vez que existe a transferência de conhecimento de uma língua para outra, faz-se necessária a exposição do aprendiz ao insumo, que é rico e necessário para que o aprendiz o processe e extraia as informações fonológicas, sintáticas, semânticas e pragmáticas, nele presente. Quando alguns subconjuntos de neurônios são mais estimulados com mais freqüência do que os outros, as experiências de mundo do aprendiz vão reforçando determinadas sinapses, o que resulta em padrões de atividades elétricas mais fortemente impressos, ou entrincheirados, do que os outros. Essas formas mais entrincheiradas podem servir como base para o
${ }^{3} \mathrm{O}$ termo entrincheiramento, do inglês entrenchment (RHODE \& PLAUT, 1999), diz respeito a uma visão conexionista do fenômeno da transferência de informaçōes neuronais durante a aprendizagem. Segundo esta concepção, conhecimentos e conceitos mais antigos, mais profundamente enraizados ou "entrincheirados" no cérebro do aprendiz, competem com os novos conhecimentos (lingüísticos ou nãolingüísticos). Zimmer (2004, 2007) propōe uma formulaçāo conexionista da transferência lingüistica como sendo o processo de entrincheiramento do conhecimento lingüistico prévio - da L1 e de outras línguas estrangeiras a que $o$ aprendiz tenha sido exposto - que modula a percepção e a produção dos padrões da L2, a partir do modelo HipCort (MCCLELLAND et al., 1995). 
aprendizado (ZIMMER \& ALVES, 2006; MOTA \& ZIMMER, 2005). Pode-se depreender desse fato que, para a aprendizagem acontecer, o aprendiz precisa ser exposto ao input significativo, o qual é carregado de regularidades que possibilitam o processamento e a formulação de regras que regem a L2. A exposição pode obedecer a uma certa freqüência, que permite que as redes neuroniais sejam reforçadas. Aliado aos fatores exposição e freqüência do input, o contexto em que ocorre a aprendizagem também desempenha um papel fundamental no processo de aquisição, especialmente no que tange à aquisição da pragmática, que requer a observação de fatores de ordem cultural, tais como a avaliação do interlocutor e as regras sociais que regem a interação.

De acordo com o paradigma conexionista, o input lingüístico é rico e fornece evidências, pistas, ensejando que o aprendiz observe as regularidades do sistema lingüístico capazes de guiar o processo de aquisição (MACWHINNEY, 2001). Dessa forma, a aquisição de uma L2 depende da atenção à estrutura do input, por meio do noticing, que será discutido na seção seguinte, da freqüência a que o aprendiz é exposto ao insumo, do contexto em que a interação ocorre e do conhecimento prévio, lingüístico e não lingüístico que o aprendiz traz consigo, durante sua trajetória rumo à língua-alvo.

Com base no conexionismo, pode-se perceber a transferência e a alternância de código como algo plenamente aceitável e saudável do ponto de vista pedagógico, pois havendo o entrincheiramento da L1 e da L2, o aprendiz faz uso de processos cognitivos com o objetivo de estabelecer a comunicação. entrincheiramento dos dois padrões lingüísticos também nos convida a refletir sobre uma metodologia "English only", uma vez que as experiências do falante com sua L1 vão estar presentes, durante o ato comunicativo.

Por fim, o conexionismo, cujo foco está no desempenho, no processamento, abre caminho para que a pragmática encontre seu posto dentro das teorias de 
aquisição de uma segunda língua, pois passa-se a investigar como o aprendiz processa, percebe, nota e, quem sabe, aprende a pragmática da L.2.

\section{Discutindo o papel da consciência e da concepção de noticing no processo de aprendizagem}

Diferentemente de outras áreas da aquisição de uma L2, que investigam principalmente a aquisição de padrões de conhecimento da interlíngua, a maioria dos estudos sobre a pragmática da interlíngua tem focado o uso da L2 em detrimento do aprendizado, da aquisição e desenvolvimento da competência pragmática da L2.

A pragmática figura como uma área relativamente nova no campo de estudos da L2 e vem fornecendo dados que mostram que falantes nativos e não-nativos apresentam diferenças, tanto de compreensão, quando de produção da língua em relação a diferentes contextos. No entanto, é necessário que se olhe para a pragmática sob o ponto de vista do desenvolvimento, do processo, e não somente do produto. Nesse sentido, o estudo de Kasper e Schmidt (1996) motiva os pesquisadores a desenvolverem mais pesquisas que abordem aspectos da aquisição e do desenvolvimento da competência pragmática. Outra área de investigação que merece o desenvolvimento de estudos diz respeito à questão da atenção e da consciência do aprendiz, no desenvolvimento da competência pragmática, e a possível relação entre consciência pragmática e gramatical.

A questão da consciência em relação ao aprendizado de uma língua estrangeira tem sido fonte de vários debates. De um lado, tem-se a visão mais tradicional de ensino, que enfatiza a importância do entendimento consciente para que se obtenha sucesso no processo de aprendizagem. Se pensarmos em implicações pedagógicas, conforme essa visão, faz-se necessária a explicitação das regras e das regularidades da língua-alvo, comparações com a L1, prática e 
correção de erros. O valor da prática, da interação, não é negado, mas geralmente a interação é precedida por explicações descontextualizadas e a pela repetição, via drills, de padrões da língua (SCHMIDT, 1995). Por outro lado, um outro ponto de vista defende a aquisição da L2 como um processo que ocorre de forma inconsciente. Assim, a aquisição se dá por meio da interação e do processamento do input, sem que haja instrução sobre as regras que regem a L2 (KRASHEN, 1982).

No entanto, há uma terceira visão, intermediária entre a oposição representada pelas duas visões acima citadas. Conforme essa visão, o foco no sentido é essencial, mas nem todas as características da língua poderão ser adquiridas, se a atenção do aprendiz estiver direcionada somente ao sentido. O foco na forma é necessário e desejável, especialmente se ocorrer dentro de um contexto comunicativo. Assim sendo, a interação, o input, a atenção e a consciência são elementos cruciais para que ocorra o aprendizado (SCHMIDT, 2001). Segundo essa visão, a instrução explícita não leva o aprendiz a automatizar o uso da língua, mas a dirigir a tomada de consciência, refletir sobre e ordenar o input recebido, a fim de facilitar o entendimento. Além disso, os aprendizes precisam aprender a prestar atenção às diferentes características de um mesmo input. Uma vez que o aprendizado acontece mediante a atenção, se alguém quiser aprender fonologia, precisa prestar atenção à fonologia; se alguém quiser aprender pragmática, precisará prestar atenção às formas lingüísticas e às características do contexto (SCHMIDT, 1995). Portanto, a atenção tornase um item essencial dentro do processo de aquisição da competência pragmática.

Um grande número de estudos relacionados ao papel da atenção na aquisição da L2 possui como ponto de partida o estudo de Schmidt (1990), em que o autor investiga a relação entre consciência e o aprendizado de uma segunda língua. Schmidt afirma que o termo "consciência" tem sido utilizado deliberadamente no campo de estudos da aquisição a L2; logo, é necessário padronizar 
a que o termo consciência se refere segundo a concepção do autor. Nesse sentido, Schmidt (1990) estabelece uma distinção entre os termos "consciência como ciência" e "consciência como intenção". A intencionalidade diz respeito ao fato de o aprendiz conscientemente tomar a decisão de aprender alguma forma de conhecimento da L2. Este trabalho refere-se à consciência como ciência (awareness), em que o aprendiz se encontra ciente dos detalhes da forma lingüística à qual é exposto.

A noção de consciência pode ser categorizada em diferentes níveis. O primeiro nível é denominado como noticing ${ }^{t}$ (notar), e este é um dos fatores necessários para que ocorra o aprendizado. Já o nível mais alto de consciência é chamado de understanding (entender). Schmidt (1995) afirma que o aprendizado não ocorrerá sem que se recorra ao noticing - o processo de prestar atenção às características lingüísticas do input. Para o autor, aquilo que o aprendiz nota no inputé o que se torna intake para o aprendizado, fato esse que caracteriza a Noticing Hypothesi". Ao afirmar que o ato de notar é necessário e suficiente para converter o input em intake, Schmidt deixa claro que só há aprendizado de qualquer aspecto lingüístico quando o input for registrado conscientemente pelo aprendiz (SCHMIDT, 1995). O autor esclarece que a percepção não ocorre sob um aspecto global, e sim sobre a forma lingüística do input, de modo que, para adquirir detalhes pragmáticos, o aprendiz deve prestar atenção especificamente a esses aspectos.

Contudo, nem todo input é convertido em intake, ou seja, nem todas as características lingüísticas do input são notadas pelo aprendiz devido a diversos fatores, como a complexidade da informação a ser processada, a maneira como a estrutura-alvo foi apresentada, a questão do contexto em que a estrutura foi trabalhada. Além disso, a atenção do aprendiz também pode estar direcionada para outros processos cognitivos, de ordem lingüística ou não (ALVES \& ZIMMER, 2005).

Portanto, podemos perceber que o aprendiz deve prestar atenção às informações contidas no input para que
4Acreditamos não haver, em português, um correspondente ideal para o substantivo noticing. Logo, optamos por manter o termo cunhado por Schmidt, conforme a língua inglesa. 
elas sejam processadas. No caso da pragmática, a atenção precisa estar voltada tanto para os aspectos lingüísticos, a forma em si, quanto para as características do contexto, da posição do interlocutor. Evidentemente, para que o aprendiz tenha chance de notar o input, é necessário que este esteja disponível para o processamento.

No caso do contexto brasileiro de ensino de uma língua estrangeira, grande parte do input é geralmente fornecida pelo professor de língua estrangeira. Nesse sentido, o inputque o professor fornece pode não conter os aspectos sociopragmáticos da língua-alvo, isto é, pode haver uma lacuna entre o enunciado produzido pelo professor brasileiro e o enunciado que um determinado contexto necessitaria. Em ambientes EFLde instrução, há a falta do chamado input autêntico e a vivência de situações reais de comunicação, as quais os aprendizes de inglês ESL estão habituados a presenciar. Além disso, existe a possibilidade de o professor utilizar o conhecimento que possui da sua L1 e transferi-lo para a L2, fato este que pode levar o falante tanto ao acerto, quanto ao erro, quer seja de ordem pragmalingüística, quer de ordem sociopragmática.

Kasper (1996) aponta a questão da saliência do input como uma das condições necessárias para a aquisição da competência pragmática. Da concepção de noticing, depreendemos que o aprendiz se encontra ciente dos detalhes da forma lingüística a que é exposto. Logo, o professor de língua estrangeira tem um papel fundamental, ao sistematizar os aspectos que caracterizam a língua-alvo e chamar a atenção dos aprendizes para esses aspectos, a fim de que o aluno aprenda de forma mais rápida tais estruturas.

Sabemos, porém, que o ensino de inglês, em contextos EFL, é primordialmente voltado para a aquisição do componente gramatical da competência comunicativa. Entretanto, esse fato não impede que passemos a instruir os aprendizes sobre a pragmática da L2, que forneçamos input que poderá prover oportunidades para que o noticing ocorra e, dessa forma, aumente as possibilidades de aprendizagem e o grau de consciência pragmática. 


\section{0 estudo empírico}

Em consonância com o estudo realizado por Bardovi-Harlig e Dörnyei (1998), investigamos se alunos proficientes, futuros professores de inglês, apresentamse conscientes quanto às inadequações pragmáticas presentes no teste de julgamento e quanto à relação entre o grau de severidade atribuído aos erros pragmáticos e gramaticais em um contexto brasileiro, o qual é composto por grupos de estudantes, em sua maioria, monolíngües que são ensinados por professores cuja língua materna é a mesma, ou seja, o português brasileiro. Neste artigo, serão contempladas as seguintes hipóteses:

1) Os aprendizes de inglês como L2 não apresentam o mesmo grau de consciência em relação às inadequações pragmáticas e gramaticais. O desempenho dos aprendizes no julgamento das inadequações gramaticais é maior do que em relação às inadequações pragmáticas.

2) O nível de proficiência lingüística do aprendiz não influencia o grau de consciência do aprendiz em relação à pragmática da L2.

\subsection{0 método}

Seleção da amostra

Com a finalidade de se chegar ao número de sujeitos que integram a amostra, elaboramos um processo de seleção para a mesma. Os seguintes critérios foram considerados para a seleção dos participantes:

a) todos os sujeitos devem ser falantes nativos do português brasileiro;

b) todos os sujeitos assinariam o Consentimento Informado;

c) todos os informantes fariam um teste de proficiência em língua inglesa (placement test), a fim de verificar o nível de proficiência lingüística dos informantes. 
Os participantes do estudo

Para a realização desta pesquisa, escolhemos trabalhar com alunos do curso de Licenciatura em Letras/ habilitação em Inglês e Literaturas de Língua Inglesa e com alunos do curso de Licenciatura em Letras/habilitação em Português/Inglês e respectivas literaturas da Universidade Federal de Pelotas. Esses alunos cursam o quinto e o sétimo semestre da graduação e foram divididos em dois grupos homogêneos, de acordo com o nível de proficiência lingüística. Ambos os grupos, experimental e de controle, são formados por 7 (sete) alunos no grupo avançado e 8 (oito) alunos do grupo intermediário-avançado advindos de qualquer uma das duas turmas. A homogeneidade em relação à proficiência deve-se ao fato de considerarmos a variável proficiência lingüística como um fator que pode influenciar a percepção da pragmática da L2 .

\section{Instrumentos}

Os instrumentos utilizados na amostragem foram os seguintes:

1) Consentimento informado e entrevista

O consentimento informado é um documento que fornece informações resumidas sobre a pesquisa a ser desenvolvida e requisita o consentimento quanto ao uso dos dados coletados para a pesquisa, mediante a assinatura do participante.

A entrevista, realizada com todos os informantes, teve duas finalidades: 1) selecionar os sujeitos cujas informações estejam de acordo com os critérios para a seleção da amostragem, tais como ser falante nativo do PB e não falar outra língua além da materna e da línguaalvo (inglês); 2) coletar dados relativos à exposição ao input, como tempo de aprendizagem e vivência no exterior, que possam auxiliar na análise qualitativa deste estudo.

2) Teste de proficiência na língua inglesa, realizado com todos os sujeitos, para estabelecer o estágio de aprendizagem da língua inglesa no qual esses sujeitos se encontram. Para a seleção dos participantes deste estudo, 
optou-se pela utilização do Oxford Placement test 1 (OPT) o qual compreende 100 questões que avaliam a competência gramatical do participante e 100 questões que avaliam a habilidade de compreensão oral. Os alunos levaram, em média, 55 minutos para completar o teste. Esse instrumento foi aplicado pela própria pesquisadora, em grupos que variaram de 7 a 15 sujeitos, dependendo do número de sujeitos presentes nas aulas de língua inglesa.

Conforme a classificação especificada pelo instrumento de avaliação da proficiência lingüística, de 25 participantes, sete alunos obtiveram resultados iguais e/ ou superiores a 150 pontos, sendo caracterizados como usuários avançados da língua inglesa. Ainda, desse universo de participantes, oito fizeram de 135 a 149 pontos, sendo caracterizados como usuários competentes pertencentes ao nível intermediário de proficiência lingüística.

3) Teste de julgamento e percepção pragmática e gramatical, desenvolvido por Bardovi-Harlig e Dörnyei (1998).

Com o propósito de investigar se os aprendizes apresentavam o mesmo grau de consciência quanto às inadequações pragmáticas e gramaticais, os autores desenvolveram um instrumento caracterizado pela exibição de um vídeo 5 (ver anexo) seguido de um questionário no qual o aprendiz realiza o julgamento de sentenças. Esse tipo de instrumento mostra-se inovador em relação à pesquisa na área da pragmática, pois o aprendiz tem a oportunidade de ver a interação, perceber o contexto em que ela ocorre e a relação entre os interlocutores, e, assim realizar o julgamento baseado na imagem, no contexto e no código lingüístico. Anteriormente, a maioria das pesquisas no campo da pragmática utilizava somente os instrumentos escritos como os $D C T$ s, visto que são fáceis de administrar, já que dependem de papel e lápis, mas que, talvez, não proporcionem a riqueza contextual oferecida pelo vídeo e a possibilidade de reflexão quanto ao julgamento da situação.

O referido teste apresenta vinte cenários, divididos em oito pragmaticamente adequados, mas que apresentam
${ }^{5}$ Agradecemos a Bardovi-Harlig e Dörnyei, por permitirem a utilização de seu instrumento de pesquisa neste estudo. 
inadequações quanto à forma; oito gramaticalmente adequados, porém inadequados quanto à pragmática; e quatro que atendem tanto à adequação pragmática como à gramatical. Os itens a serem julgados foram alocados em quatro grupos de cinco cenários com as sentenças a serem observadas. Cada grupo apresenta duas sentenças agramaticais, mas pragmaticamente adequadas, duas pragmaticamente inadequadas, mas gramaticais e uma que obedece aos dois quesitos de adequação. Cabe ressaltar que o teste de julgamento e percepção apresenta quatro atos de fala: a) pedidos de desculpa; b) realização de pedidos; c) recusas; e d) sugestões, porém não há uma divisão homogênea quanto à ocorrência de cada ato de fala, fato corroborado pela afirmação dos autores, que explicam que os itens foram organizados fortuitamente.

Quanto à execução do teste, o participante, primeiramente, escuta as instruções para a realização do teste e também pode lê-las no questionário. Após ouvir as instruções, assiste a uma cena que contém uma inadequação pragmática e o narrador explica que a resposta dada pelo falante da cena não foi adequada (it was not good) e ensina como marcar a resposta no questionário. O participante é instruído a, no primeiro momento, só assistir a cena, e depois, assistir a cena novamente e marcar a resposta no questionário. Para que o aprendiz-participante identifique a sentença-alvo do julgamento, o vídeo mostra uma tela azul com um ponto de exclamação que precede a sentença a ser avaliada. Se a sentença for considerada inadequada, o participante deve julgar a severidade da inadequação em uma escala presente no questionário, como pode ser observado no exemplo a seguir:

1. The teacher asks Peter to help with the plans for the class trip.

T: OK, so we'll go by bus. Who lives near the bus station? Peter, could you check the bus times for us on the way home tonight?

P: No, I can't tonight. Sorry. 
A sentença a ser julgada aparece sob o seguinte formato:

1. ! No, I can't tonight. Sorry.

Was the last part appropriate / correct?

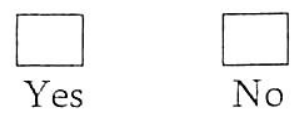

If there was a problem, how bad do you think it was?

Not bad at all __________________ Very bad

Para completar a tarefa, os participantes primeiramente julgam se a sentença-alvo é apropriada ou não. Logo após, eles devem classificar a gravidade do problema em uma escala com seis pontos que variam entre aceitávele muito ruim.

\section{Analisando os resultados}

A análise do desempenho dos participantes no teste de julgamento parte das hipóteses de que os aprendizes de inglês não apresentam o mesmo grau de consciência em relação às inadequações pragmáticas e gramaticais e de que o nível de proficiência não influencia o grau de consciência do aprendiz em relação à pragmática da L2. Cabe lembrar que os participantes foram divididos em dois grupos, conforme o nível de proficiência de cada um, e testados individualmente.

\subsection{Amostra dos participantes do nível intermediário}

Conforme os dados verificadós na Tabela 1 , podese perceber que os sujeitos de nível intermediário obtiveram um melhor desempenho no julgamento (percepção de erros) gramatical do que no julgamento de inadequações pragmáticas; contudo esse desempenho não foi estatisticamente significativo. Os dados apresentamse em conformidade com o estudo conduzido por BardoviHarlig e Dörnyei (1998) no que tange ao reconhecimento 
de erros gramaticais ainda que os dados não se mostrem estatisticamente significativos.

\begin{tabular}{c|c|c}
\hline Sujoitos & $\begin{array}{c}\text { Acortos } \\
\text { Gramaticais }\end{array}$ & $\begin{array}{c}\text { Acertos } \\
\text { pragmáticos }\end{array}$ \\
\hline 1 & 62,5 & 50 \\
2 & 62,5 & 50 \\
3 & 75 & 87.5 \\
4 & 87.5 & 75 \\
5 & 37.5 & 50 \\
6 & 87.5 & 37.5 \\
7 & 87.5 & 37.5 \\
8 & 75 & 100 \\
\hline
\end{tabular}

sujeitos do nível intermediário

Tabela 1 - Percentual de acertos no julgamento de desvios gramaticais e pragmáticos:

\subsection{Amostra dos sujeitos do nível avançado}

Os sujeitos do nível avançado tiveram um melhor desempenho no julgamento pragmático (ver Tabela 2), mas essa diferença também não foi significativa. No entanto, a maior percepção dos desvios pragmáticos por parte dos sujeitos avançados motiva o estudo, no sentido de investigar se uma maior consciência pragmática se reflete em uma produção pragmática adequada. O número pequeno de participantes possivelmente se reflete na questão de os dados não se mostrarem significativos, fato este que faz com que o pesquisador tenha de interpretar os dados com mais cuidado.

\begin{tabular}{c|c|c}
\hline Sujeitos & $\begin{array}{c}\text { Acertos } \\
\text { Gramaticais }\end{array}$ & $\begin{array}{c}\text { Acertos } \\
\text { pragmáticos }\end{array}$ \\
\hline 1 & 37.5 & 100 \\
2 & 62,5 & 50 \\
3 & 87,5 & 62.5 \\
4 & 75 & 75 \\
5 & 50 & 100 \\
6 & 87,5 & 62.5 \\
7 & 37,5 & 75 \\
\hline
\end{tabular}

Tabela 2 - Percentual de acertos no julgamento de desvios gramaticais e pragmáticos: sujeitos de nível avançado 
Uma vez apresentados os dados referentes aos resultados dos dois grupos, passamos agora à avaliação das hipóteses desta pesquisa.

\subsection{Avaliação das hipóteses}

A primeira hipótese, os aprendizes de inglês não apresentam o mesmo grau de consciência em relação às inadequações pragmáticas e gramaticais, foi refutada. Houve pequena diferença entre os testes de julgamento gramatical e pragmático, mas essa diferença não foi significativa. Esperávamos que os sujeitos mais proficientes tivessem um melhor desempenho no reconhecimento das inadequações gramaticais, pois, conforme Bardovi-Harlig (1991), o currículo, que serve como base para a prática dos professores e ensino dos alunos, é primordialmente voltado para a atenção à gramática da língua. Além disso, Bardovi-Harlig e Dörnyei (1998) verificam que o contexto onde a língua é ensinada é relevante, no que diz respeito ao desenvolvimento da consciência pragmática, isto é, aprendizes imersos em um contexto ESL têm maior chance de reconhecer inadequações pragmáticas devido à exposição ao input autêntico e ao contato com falantes nativos que carregam consigo valores de ordem cultural.

No estudo conduzido por Niezgoda e Röver (2001), também é possível notar que não houve diferença significativa entre o reconhecimento dos erros pragmáticos entre os sujeitos de maior e menor proficiência lingüística (78\% versus $86 \%)$

A segunda hipótese, o nível de proficiência lingüística do aprendiz não influencia o grau de consciência do aprendiz em relação à pragmática da L2, foi corroborada. O que podemos concluir, diferentemente de Bardovi-Harlig e Dörnyei, é que a variável proficiência lingüística não exerceu um efeito sobre o grau de consciência pragmática nem gramatical.

Cabe lembrar que as situações apresentadas no vídeo representam cenas da vida universitária, comuns ao cotidiano dos sujeitos da pesquisa. Logo, eles podem fazer 
relações entre os itens pragmáticos e sua experiência na universidade. Fica aberta a questão de como esses mesmos sujeitos se comportariam em cenários diferentes, tais como restaurantes, lojas e entre amigos, em que teriam que se comunicar na língua estrangeira.

\section{Considerações finais}

Conforme colocado anteriormente, Schmidt (1995) afirma que se alguém deseja aprender pragmática, deve prestar atenção ao aspecto pragmático do input. $\mathrm{O}$ professor de LE pode fornecer input que poderá ensejar oportunidades para que o noticing ocorra e, dessa forma, aumente as possibilidades de aprendizagem, bem como o grau de consciência pragmática.

O objetivo maior do projeto de pesquisa em que o presente trabalho se insere é o de promover o noticing via instrução explícita. Os resultados apresentados referemse aos pré-testes de julgamento; a próxima etapa compreende cinco encontros em que o aspecto pragmático da L2 será trabalhado através da instrução de caráter explícito.

Espera-se que as sessões de orientação explícita com o grupo experimental (sujeitos de nível avançado) sirvam para orientar os aprendizes sobre suas escolhas pragmáticas e as conseqüências que tais escolhas possam desencadear.

Por fim, a pesquisa ainda investigará se a instrução explícita aumenta a consciência pragmática e influencia uma produção pragmática adequada. Além disso, também será investigado se haverá diferença entre a atribuição de valores dada pelos sujeitos participantes da pesquisa, ao julgar enunciados pragmático e gramaticalmente inadequados.

A competência pragmática do aprendiz aumentará somente se houver inputque contenha as características e estruturas da língua-alvo; se o input for notado e analisado em todos os seus aspectos, e processado como conhecimento aprendido. 


\section{Referências}

ALVES, Ubiratã Kickhöfel. O papel da instrução explícita na aquisição fonológica do inglês como L2:evidências fornecidas pela teoria da otimidade. 2004. 335 f. Dissertação (Mestrado) Universidade Católica de Pelotas, Pelotas-RS, 2004.

; ZIMMER, Márcia C. Perceber, notar e aprender: uma visão conexionista da consciência do aprendiz na aquisição fonológica da L2. Revista virtual de estudos da linguagemReVEL. Ano 3, n. 5, 2005. [Disponível em www.revelhp.cjb.net] BACHMAN, Lyle. Fundamental consideration in language testing. New York: Oxford University Press, 1990.

BARDOVI-HARLIG, Kathleen; DÖRNYEI, Zoltan. Do students recognize pragmatics violations? Pragmatics versus grammatical awareness in instructed L2 learning. TESOL Quartely, n. 32, 1998, $233-262$.

CANALE, Michael. From communicative competence to language pedagogy. In.: RICHARDS, J.; SCHMIDT, R. (Eds.). Language and communication. London: Longman, 1983. ; SWAIN, Michelle. Theoretical bases of communicative approaches to second language teaching and testing. Applied linguistics, n. 1, p.1-47, 1980.

CHOMSKY, Noam . Aspects of the theory of syntax. Cambridge: Cambridge University Press, 1965.

COOK, Vivian. Linguistics and second language acquisition: one person with two languages. In.: ARONOFF, Mark; REESMILLER, Janie. The handbook of linguistics. Oxford: Blackwell, 2003. p. $488-511$.

HYMES, Dell. On communicative competence. In: PRIDE, J.; HOLMES, J. (Eds). Sociolinguistics. London: Penguin, 1972.

LEVINSON, Stephen. Pragmatics. Cambridge: Cambridge University Press, 1983.

KASPER, Gabrielle. (1996). Introduction: Pragmatics in SLA. Studies in second language acquisition, 18, 145-149, 1996. ; ROSE, Kenneth. Pragmatics in language teaching. New York: Cambridge University Press, 2001 
; SCHMIDT, Richard. Developmental issues in

interlanguage pragmatics. Studies in second language acquisition, n. $18,149-169,1996$.

KRASHEN, Steven. Second language acquisition and second language learning. Oxford: Pergamon Press, 1982.

LEECH, G. N. Principles of pragmatics. London: Longman, 1983.

MACWHINNEY, Brian. The competition model: the input, the context, and the brain. In: RoBinsons, P. (Ed) Cognition and second language instruction. Cambridge: CUP, 2001 . p. 69-90. MCCLELLAND, James; McNAUGHTON, Bruce; O'REILLY, Randall. Why there are complementary learning systems in the hippocampus and neocortex: insights from the successes and failures of connectionist models of learning and memory. Psychological review, v. 102, n. 103, p. 419-457, 1995.

MOTA, Mailce Borges; ZIMMER, Márcia Cristina. Cognição e aprendizagem de L2: o que nos diz a pesquisa nos paradigmas simbólico e conexionista. Revista brasileira de lingüiśstica aplicada, v. 5, n. 2, p. 155-187, jul-dez 2005.

NAIDITCH, Fernando. Transferência pragmática, culturale interlíngua: o caso dos pedidos de permissão. 1998. $194 \mathrm{f}$. Dissertação (Mestrado) - Universidade Federal do Rio Grande do Sul, Porto Alegre, 1998.

NIEZGODA, Kimberly; ROVER, C. Pragmatics in language teaching. Cambridge: Cambridge University Press, 2001.

RHODE, Douglas; PLAUT, David. Language acquisition in the absence of of explicit negative evidence: how important is starting small? Cognition, n. 72, p. 67-109. 1999.

SCHAUER, Gilla. Pragmatic awareness in ESL and EFL contexts: contrast and development. Language learning, n. 56, p. 269318, 2006.

SCHMIDT, Richard. The role of consciousness in second language learning. Applied linguistics, n. 11, p. 129-158, 1990. . Attention and awareness in foreign language learning. Honolulu: HI, University of Hawaii Press, 1995. 
. Attention. In.: ROBINSON, Peter. Cognition and second language instruction. Cambridge: Cambridge University Press, 2001. p. 3-32.

SELINKER, Larry. Interlanguage. IRAL, n. 10, p. 209-231, 1972.

ZIMMER, Márcia Cristina. A transferência do conhecimento fonético-fonológico do português brasileiro (L1) para o inglês (L2) na recodificação leitora: uma abordagem conexionista. 2004. 187f. Tese (Doutorado) - Pontifícia Universidade Católica do Rio Grande do Sul, Porto Alegre, 2004.

ZIMMER, Márcia Cristina. A aprendizagem hebbiana, o modelo HipCort e a produção oral em L2: uma abordagem conexionista. Anais do 7 encontro nacional de aquisição da linguagem. Porto Alegre, 2007 (no prelo).

ZIMMER, Márcia Cristina; ALVES, Ubiratã Kickhöfel. A produção de aspectos fonéticos/fonológicos da L2: instrução explícita e conexionismo. Linguagem \& Ensino, v. 9, p. 101-143, jul-dez 2006. 


\section{Anexo - Test of pragmatic and grammatical judgment}

SCENES FROM SCHOOL

The text for the 20 scenarios

1. The teacher asks Peter to help with the plans for the class trip.

T: OK, so we'll go by bus. Who lives near the bus station? Peter, could you check the bus times for us on the way home tonight?

P: No, I can't tonight. Sorry.

2. Peter and George are classmates. George invites Peter to his house, but Peter cannot come.

G: Peter, would you like to come over to my house tonight?

P: I'm sorry, I just can't. I'm very tired. I couldn't sleep on last night.

3. Peter goes to the snack bar to get something to eat before class.

F: May I help you?

P: Would you be so kind as to give me a sandwich and a yoghurt please?

4. George is going to the library. Peter asks him to return a library book.

G: Well, I'll see you later. I've got to go to the library to return my books.

P: Oh, if you are going to the library, can you please return my book too?

5. Peter is talking to his teacher. The conversation is almost finished.

T: Well, I think that's all I can help you with at the moment.

P: That's great. Thank you so much for all the informations.

6. Anna is talking to her teacher in his [sic!] office when she knocks over some books.

A: (knocks over some books) Oh no! I'm really sorry! Let me help you pick them up. 
7. It is Anna's day to give her talk in class, but she is not ready.

T: Thank you Steven, that was very interesting. Anna, it's your turn to give your talk.

A: I can't do it today but I will do it next week.

8. Anna goes to the snack bar to get something to eat before class.

F: May I help you?

A: A cup of coffee please.

F: Would you like some cream in it?

A: Yes, I would like.

9. Anna has borrowed a book from a classmate, Maria. Maria needs it back, but Anna has forgotten to return it.

M: Anna, do you have the book I gave you last week?

A: Oh, I'm really sorry but I was in a rush this morning and I didn't brought it today.

10. Anna needs directions to the library. She asks another student.

A: $\mathrm{Hi}$.

S: $\mathrm{Hi}$.

A: Tell me how to get to the library.

11. Peter is going to George's house. He is quite late.

P: Hi George.

G: Hi Peter. I've been waiting for over half an hour for you. Weren't we supposed to meet at 4?

P: I couldn't come earlier. And anyway, we don't have to hurry anywhere.

12. Peter and George meet before class. They want to do something before class starts.

G: Hey, we've got 15 minutes before the next class. What shall we do?

P: Let's to go to the snack bar.

13. Peter goes to see his teacher at his office. When he arrives, his teacher is busy. 
P: (knocks on the door)

T: Yes, come in.

P: Hello, Mr. Gordon. Are you busy?

T: Erm... I'm afraid so. Could you come back later?

P: $\quad$ OK, I'll be here tomorrow morning at 8 .

14. Peter asks his teacher for a book.

P: Mr. Gordon?

G: Yes?

P: Could I possibly borrow this book for the weekend if you not need it?

15. Peter's teacher wants to talk to Peter about the class party. Peter makes arrangements to come back.

T: Peter, we need to talk about the class party soon.

P: Yeah, if tomorrow is good for you, I could come any time you say.

16. Anna goes to ask her teacher to fill in a questionnaire. She knocks on the office door.

A: (knocks on the door)

T: Yes, come in.

A: Hello. My name is Anna Kovacs. If you don't mind, I would like you to fill this in for me.

17. Maria invites Anna to her house but Anna cannot come.

M: Anna, would you like to come over this afternoon?

A: I'm sorry, I'd really like to come but I have a difficult history test tomorrow.

18. Anna needs directions to the library. She asks another student.

A: Excuse me, could you tell me where is the library.

19. Anna has borrowed a book from her teacher. Her teacher needs it back, but Anna has forgotten to return it.

$\mathrm{T}$ : Anna, have you brought back the book I gave you yesterday?

A: Oh, I'm very sorry, I completely forgot. Can I giving it to you tomorrow? 
20. Anna meets her classmate, Maria, after school. They want to go somewhere.

A: Maria, are you doing anything this afternoon?

M: No, I've already prepared for tomorrow's classes.

A: Then I say we go to the cinema. OK? 